\title{
ATIVIDADE ALELOPÁTICA DE EXTRATO AQUOSO DE Eucalyptus grandis Hill ex Maiden SOBRE ALFACE (Lactuca sativa L.) e PICAO-PRETO (Bidens pilosa L.)
}

\author{
ALELOPATHIC ACTIVITY OF AQUEOUS EXTRACT OF Eucalyptus grandis Hill ex \\ Maiden ON LETTUCE (Lactuca sativa L.) AND BEGGARTICKS (Bidens pilosa L.)
}

\author{
ACTIVIDAD ALELOPÁTICA DEL EXTRACTO ACUOSO DE Eucalyptus grandis Hill ex Maiden \\ SOBRE LECHUGA (Lactuca sativa L.) y CHIPACA (Bidens pilosa L.)
}

\author{
Rafael Zorzenoni Espinosa* \\ rafaellze@hotmail.com \\ Flávia Helena de Moura Libório * \\ flaviahfmoura@gmail.com \\ Luciano Ivano da Silva ** \\ lucianobiopr@yahoo.com.br \\ Patricia da Costa Zonetti*** \\ patricia.zonetti@gmail.com \\ Anny Rosi Mannigel* \\ armannigel@gmail.com \\ Daniele Fernanda Felipe* \\ daniele.felipe@uol.com.br
}

\author{
Aline Maria Orbolato Gonçalves-Zuliani* \\ alineorb@hotmail.com \\ Graciene de Souza Bido*,* \\ gsbido@hotmail.com \\ * Centro Universitário de Maringá - UNICESUMAR, Maringá-PR - Braisl \\ ** Universidade Estadual de Maringá - UEM, Maringá-PR - Brasil \\ ** Universidade Federal do Paraná - UFPR, Palotina-PR - Brasil
}

\section{Resumo}

Planta invasora de difícil controle, o picão-preto (Bidens pilosa L.) pode ser encontrado em quase todo o Brasil, inclusive nas áreas agrícolas ocupadas com espécies olerícolas, como a alface (Lactuca sativa L.). O controle das plantas invasoras tem sido realizado principalmente pelo uso de herbicidas, promovendo impacto ambiental e risco a saúde humana e animal. Assim, o objetivo deste trabalho foi avaliar o potencial alelopático do extrato aquoso de folhas secas de Eucalyptus grandis Hill ex Maiden sobre a germinação e o crescimento inicial de alface e picão-preto. Foram analisadas quatro concentrações do extrato aquoso (25, 50, 75 e 100\%), além da testemunha $(0 \%)$. $\mathrm{O}$ delineamento experimental foi inteiramente casualizado, com três repetições de cada tratamento, constituídas por 50 sementes de alface ou picão-preto distribuídas em gerbox e mantidas em câmara tipo B.O.D com fotoperíodo de $12 \mathrm{~h}$ a $25^{\circ} \mathrm{C}$ por 7 dias. Os resultados obtidos indicaram que Eucalyptus grandis Hill ex Maiden não apresentou potencial alelopático em relação às plântulas de picão-preto e a baixas concentrações pouco influenciou a germinação e o crescimento inicial de plântulas de alface.

Palavras-Chave: Alelopatia. Controle alternativo. Horticultura.

\section{Abstract}

Invasive plant of difficult control, the beggarticks (Bidens pilosa L.) can be found almost all over Brazil, including agricultural areas occupied with olericultural species such as lettuce (Lactuca sativa L.). The control of invasive plants has been performed mainly by the use of herbicides, promoting environmental impact and risks to human and animal health. Thus, the objective of this work was to evaluate the allelopathic potential of the dried leaves aqueous extract of 
Eucalyptus grandis Hill ex Maiden on the germination and initial growth of lettuce and beggarticks. Four concentrations of the aqueous extract $(25,50,75$ and $100 \%)$ and the control $(0 \%)$ were analyzed. The experimental design was completely randomized, with three replications of each treatment, consisting of 50 seeds of lettuce or beggarticks, distributed in gerbox and kept in B.O.D chamber with photoperiod of $12 \mathrm{~h}$ at $25^{\circ} \mathrm{C}$ for 7 days. The results indicated that Eucalyptus grandis Hill ex Maiden did not show allelopathic potential in relation to the beggarticks seedlings and the low concentrations had little influence on the germination and initial growth of lettuce seedlings.

Keywords: Allelopathy. Alternative control. Horticulture.

\section{Resumen}

Una planta invasora difícil de controlar, la chipaca (Bidens pilosa L.) se puede encontrar en casi todo Brasil, incluso en áreas ocupadas por especies olerícolas como la lechuga (Lactuca sativa L.). El control de plantas invasoras se ha realizado principalmente mediante el uso de herbicidas, promoviendo el impacto ambiental y el riesgo para la salud humana y animal. Por lo tanto, el objetivo de este trabajo fue evaluar el potencial alelopático del extracto acuoso de hojas secas de Eucalyptus grandis Hill ex Maiden en la germinación y crecimiento inicial de lechuga y chipaca. Se analizaron cuatro concentraciones del extracto acuoso $(25,50,75$ y $100 \%)$ y el control (0\%). El diseño experimental fue completamente al azar, con tres repeticiones de cada tratamiento, que consistía en 50 semillas de lechuga o chipaca distribuidas en gerbox y mantenidas en una cámara tipo B.O.D con fotoperíodo de $12 \mathrm{~h}$ a $25^{\circ} \mathrm{C}$ durante 7 días. Los resultados indicaron que Eucalyptus grandis Hill ex Maiden no presentaba potencial alelopático en relación con las plántulas de chipaca y en bajas concentraciones poca influencia en la germinación y el crecimiento inicial de las plántulas de lechuga.

Palabras clave: Alelopatía. Control alternativo. Horticultura.

\section{INTRODUÇÃO}

As plantas invasoras competem com as culturas por fatores como água, luz, nutrientes e espaço físico (PEREIRA et al., 2011; SOARES et al, 2019; VASCONCELOS et al., 2012), também agem como hospedeiros de pragas e doenças e interferem inclusive sobre a quantidade e qualidade dos frutos produzidos (ALVINO et al., 2011; CUNHA et al., 2015).

Dentre as plantas invasoras de difícil controle destaca-se o picão-preto (Bidens pilosa L.), uma espécie herbácea anual, originária da América do Sul (SILVA et al., 2011; BARTOLOME et al., 2013; GILBERT et al. , 2013). No Brasil é encontrada em quase todo o território, porém concentra-se nas áreas agrícolas das regiões Sul e Centro Oeste (FORMAGIO et al., 2012). Constitui uma das mais importantes plantas invasoras de culturas anuais e perenes, sendo sua presença quase que constante em todas as épocas do ano (SANTOS e CURY, 2011), instalando-se em áreas ocupadas com espécies olerícolas como a alface. É uma invasora bastante agressiva, que além de competir com a cultura pode servir de hospedeiro de pragas e doenças e liberar compostos alelopáticos que inibem o desenvolvimento de hortaliças e provocar perdas significativas de produtividade em culturas agrícolas (MOREIRA e BRAGANÇA, 2011; FORMAGIO et al., 2012).

O controle das plantas invasoras tem sido realizado primordialmente pelo uso de herbicidas (DECHOUM e ZILLER, 2013), os quais se caracterizam como uma das opções mais eficientes, principalmente em extensas áreas de plantio com alta infestação (ALVINO et al., 2011), porém os 
mesmos têm sido condenados pelo impacto ambiental que produzem e o risco a saúde humana e animal (GRISI et al., 2012; CASSAL et al., 2014).

A horticultura é responsável por grande parte da utilização destes produtos, muitas vezes realizando pulverizações para o controle de pragas e doenças semanalmente (ALMEIDA et al., 2009). Um terço dos alimentos consumidos cotidianamente pelos brasileiros está contaminado pelos agrotóxicos, o caso mais grave é o do pimentão com 92\% das amostras irregulares, contra $63 \%$ dos morangos, $57 \%$ do pepino, $54 \%$ das amostras de alface e $50 \%$ de cenoura (CASSAL et al., 2014).

A alface (Lactuca sativa L.) é considerada a hortaliça folhosa mais consumida no Brasil e no mundo, é uma espécie com grande valor econômico e alimentar e seu cultivo é realizado comumente por pequenos e médios produtores (DIAMANTE et al., 2013; CARVALHO e SABBAG, 2015). Segundo Ferreira e Áquila (2000), essa espécie é considerada uma planta indicadora da atividade alelopática, pois a mesma apresenta germinação rápida e uniforme e grau de sensibilidade que permita expressar os resultados sob baixas concentrações das substâncias alelopáticas. Trabalhos visando diferentes efeitos alelopáticos sobre essa cultura já foram realizados por Alves et al. (2011), Costa et al (2019), Souza e Cardoso (2013), Klein et al. (2014), Parente et al. (2015), Gonçalves et al. (2016) e Zera et al (2019).

As interações alelopáticas acontecem através de substâncias químicas liberadas no meio ambiente por plantas ou micro-organismos que influenciem o crescimento e desenvolvimento de sistemas biológicos, ocasionando efeitos direto ou indireto, benéfico ou prejudicial (GOLDFARB et al. 2009; SALDANHA, 2013). É um importante mecanismo ecológico que influencia a dominância e sucessão das plantas, cujas interações são responsáveis pelo estabelecimento e sobrevivência de espécies no ambiente (SILVA, 2018).

Os aleloquímicos podem oferecer novas e excelentes oportunidades para diversificar o controle de plantas invasoras nas culturas, reduzindo ou eliminando a contaminação do ambiente, preservando os recursos naturais e garantindo o oferecimento de produtos agrícolas com alta qualidade, desprovidos de resíduos contaminantes (GUSMAN et al., 2012).

Dentre as espécies com possível potencial alelopático destaca-se o gênero Eucalyptus. Os eucaliptos são oriundos da Austrália, pertencem à família Myrtaceae e compreendem cerca de 900 espécies e subespécies arbóreas de rápido crescimento, amplamente utilizadas na obtenção de madeira e cultivadas em todo mundo, o que reduz a exploração de espécies nativas (GILLES et al., 2010; 
ARAUJO et al., 2012; SEBEI et al., 2015). Também apresentam alto teor de compostos fenólicos, os quais possuem atividade antioxidante (HAIDA et al., 2011).

O gênero Eucalyptus tem várias espécies consideradas alelopáticas e que podem interferir na germinação, crescimento e desenvolvimento de diversas espécies de interesse florestal ou agrícola, como as hortaliças (TOLEDO et al, 2018; YAMAGUSHI et al., 2011; SOUZA e CARDOSO, 2013; SILVA et al., 2015; CARVALHO et al., 2015; ALEIXO et al., 2016; MARCON et al., 2016; SHETTA et al., 2017). Em pequenas propriedades é comum a produção de hortaliças próximo a eucaliptos, sendo frequente a observação de características que comprovem seu efeito alelopático significativo (CREMONEZ et al., 2013).

Deste modo, comprova-se que as folhas de várias espécies de eucaliptos são fonte de compostos alelopáticos em potencial, com vasta atividade biológica que possibilita auxiliar no controle biológico de insetos, doenças e plantas invasoras. Sendo assim, o objetivo deste trabalho foi avaliar o potencial alelopático do extrato aquoso de folhas secas de Eucalyptus grandis Hill ex Maiden sobre a germinação e o crescimento inicial de sementes de (Lactuca sativa L.) e (Bidens pilosa L.).

\section{PERCURSO METODOLÓGICO}

\section{Material vegetal}

Folhas jovens de eucalipto (Eucalyptus grandis Hill ex Maiden) foram providas de podas semanais de mudas de um viveiro localizado no distrito de Iguatemi, município de Maringá-PR. As sementes de alface (Lactuca sativa L.) cv. "Regina" e picão-preto (Bidens pilosa L.) foram obtidas no comércio devidamente certificado.

\section{Obtenção do extrato aquoso}

Após a coleta, as folhas frescas foram colocadas em sacos de papel e desidratadas em estufa a $60 \pm 1^{\circ} \mathrm{C}$ até atingirem peso constante. Os extratos foram preparados conforme metodologia proposta por Thomazini et al. (2000) com modificações, onde 25 gramas de folhas secas e picadas manualmente foram adicionadas a $200 \mathrm{~mL}$ de água destilada, então trituradas em liquidificador por 5 minutos. A solução obtida foi mantida por 24 horas em repouso para extração dos compostos hidrossolúveis em recipiente âmbar para evitar a fotodegradação. Foi então realizada filtração em gaze e o extrato obtido foi considerado extrato bruto $100 \%$, a partir do qual foram realizadas diluições em 
água destilada e estabelecidos cinco tratamentos: 0 (testemunha); 25; 50; 75 e 100\%. A testemunha (0\%) foi constituída apenas por água destilada.

\section{Condução experimental}

Antes da montagem e avaliações de cada experimento, as mãos, bancadas, câmara de germinação e materiais utilizados passaram por procedimento de desinfecção, através da utilização de álcool 70\%, já as sementes foram previamente mergulhadas em solução de hipoclorito de sódio ( $\mathrm{NaClO})$ a $2 \%$, por 1-2 minutos, para descontaminação das mesmas e em seguida lavadas abundantemente com água destilada.

As sementes de alface ou picão-preto foram distribuídas aleatoriamente em gerbox $(11 \mathrm{x} 11 \mathrm{x}$ $3,5 \mathrm{~cm}$ ) sobre duas folhas de papel de Germitest ${ }^{\circ}$ (previamente autoclavada a $121{ }^{\circ} \mathrm{C}$, por 20 minutos). Os gerbox, contendo 25 sementes e $10 \mathrm{~mL}$ do extrato aquoso ou água destilada, foram mantidos em câmara de germinação tipo B.O.D à $25 \pm 1^{\circ} \mathrm{C}$ e fotoperíodo de 12 horas, sendo a luz do dia simulada por quatro lâmpadas brancas fluorescentes de $25 \mathrm{~W}$, por um período de sete dias (BORELLA e PASTORINI, 2009).

Após 48 horas de incubação, foram acrescentados mais $5 \mathrm{~mL}$ de extrato aquoso ou água destilada nos gerbox, de acordo com o respectivo tratamento, para manutenção da umidade. O registro da germinação foi realizado em intervalos de 24 horas durante 7 dias, considerando como critério de germinação a profusão de $2 \mathrm{~mm}$ da raiz primária, segundo metodologia descrita nas Regras para Análise de Sementes (BRASIL, 2009).

\section{Germinação}

O número de sementes germinadas foi contabilizado obtendo a porcentagem de germinação (PG) e o índice de velocidade de germinação (IVG) ao final de sete dias, segundo Ferreira e Borghetti (2004).

A porcentagem de germinação (PG) foi obtida pela representação da porcentagem de sementes germinadas em relação ao número de sementes dispostas a germinar sob as determinadas condições experimentais, dada por:

$\mathrm{PG}=\left(\Sigma\right.$ ni. $\left.\mathrm{N}^{-1}\right) \cdot 100$

Onde:

$\Sigma$ ni = número total de sementes germinadas;

$\mathrm{N}^{-1}=$ número de sementes dispostas para germinar. 
O índice de velocidade de germinação (IVG) foi obtido pela somatória dos números de sementes germinadas a cada dia dividido pelo número de dias decorridos entre a semeadura e a germinação, o IVG é dado por:

$\mathrm{IVG}=(\mathrm{G} 1 / \mathrm{N} 1)+(\mathrm{G} 2 / \mathrm{N} 2)+(\mathrm{G} 3 / \mathrm{N} 3)+\ldots .+(\mathrm{Gn} / \mathrm{Nn})$

Onde:

$\mathrm{G}=$ número de sementes;

$\mathrm{N}$ = número de dias após a semeadura.

\section{Crescimento inicial}

O crescimento inicial das plântulas de alface e picão foi determinado pelo comprimento da parte aérea (CPA) e da raiz (CR) além das massas fresca (MF) e seca (MS) das plântulas.

O comprimento de parte aérea (CPA) foi obtido pela medida da distância entre o colo e ápice da parte aérea, enquanto o comprimento de raiz (CR) foi determinado pela medida da distância entre o colo e o ápice da raiz primária, para averiguação de ambos os comprimentos foi utilizada uma régua milimetrada e os resultados foram expressos em centímetro (cm) (KLEIN et al., 2014). Somente foram mesuradas as plântulas com capacidade de desenvolvimento (BRASIL, 2009).

A massa fresca (MF) e massa seca (MS) das plântulas de alface e picão-preto foram verificadas em balança analítica e os resultados foram expressos em gramas (g). A MF foi determinada imediatamente após as plântulas serem retiradas do gerbox e a MS foi obtida depois de permanecerem devidamente acondicionadas em estufa, a $60^{\circ} \mathrm{C}$, até peso constante (BORELLA e PASTORINI, 2009).

\section{Delineamento experimental e análise estatística}

O delineamento experimental foi inteiramente casualizado com três repetições de cada tratamento. Os dados foram submetidos à análise de variância (ANOVA) utilizando o programa estatístico SISVAR (FERREIRA, 2011) e as médias comparadas pelo teste de Scott Knott a 5\% de significância (SCOTT e KNOTT, 1974).

\section{RESULTADOS E DISCUSSÕES}

O extrato aquoso de Eucalyptus grandis Hill ex Maiden reduziu a porcentagem de germinação (PG) da alface a partir da concentração de 50\% (Figura 1A) enquanto que, seu índice de velocidade de 
germinação (IVG) diminui progressivamente com o aumento da concentração do extrato aquoso (Figura 1B). Entretanto não houve alteração significativa da PG e IVG do picão preto (Figura 1A e B).
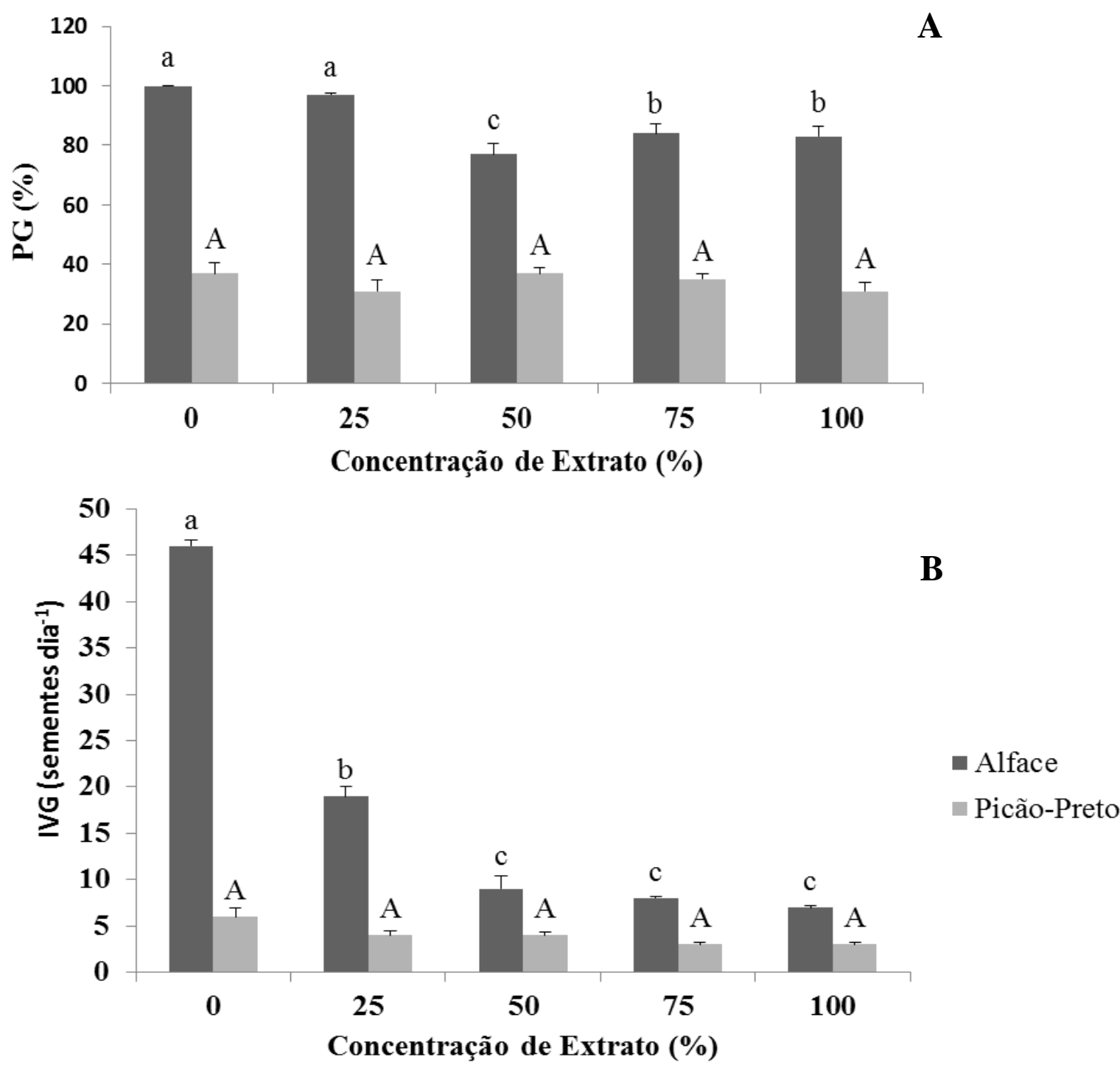

Figura 1 - A - Porcentagem de germinação (PG) e B - Índice de velocidade de germinação (IVG) de plântulas de alface e picão-preto tratadas com diferentes concentrações $(0,25,50,75$ e $100 \%)$ de extrato aquoso de Eucalyptus grandis Hill ex Maiden durante sete dias. Médias com letras distintas diferem entre si $(\mathrm{p} \leq 0,05)$ pelo teste de Scott Knott e as barras correspondem ao erro padrão (SE). Letras minúsculas referem-se à alface e letras maiúsculas ao picão-preto.

Resultados semelhantes foram encontrados por Souza e Cardoso (2013) que ao utilizar extrato aquoso de folhas de Eucalyptus grandis Hill ex Maiden também observaram redução da PG das sementes de alface quando tratadas com extratos nas concentrações de $50 \%, 75 \%$ e $100 \%$, sendo que na 
concentração de 100\% nenhuma semente germinou. Silva et al. (2015), ao analisar o potencial alelopático de extratos aquosos de folhas de desta mesma espécie de eucalipto, observaram inibição da germinação de sementes e IVG de Ipomoea purpurea L., outra planta daninha que causa prejuízos em sistemas olerícolas. Shetta et al. (2017), utilizando extrato aquoso de folhas de Eucalyptus obtusa e Eucalyptus intertexa, constataram que nas maiores concentrações do extrato aquoso a germinação e o crescimento de plântulas de Acacia ehrenbergiana, A. tortolis e A. gerrardii reduziram significativamente quando comparadas ao controle.

Os eucaliptos são caracterizados pela presença de óleos voláteis que apresentam potencial alelopático sobre outras plantas, interferindo em processos fisiológicos, padrão de germinação e crescimento de muitas plantas. Os monoterpenóides formam a maioria dos óleos essenciais das plantas e são, dentro desse grupo, os que têm sido identificados com maior potencialidade inibitória. Diversas espécies de Eucalyptus produzem produtos voláteis tóxicos como canfeno, dipenteno, $\alpha$-pineno e $\beta$ pineno que inibem o desenvolvimento de outras plantas (ALMEIDA, 1988).

Ferreira e Aquila (2000) destacam que o efeito alelopático sobre a velocidade de germinação pode ser mais expressivo em relação a porcentagem de germinação total. De acordo com Ferreira e Borghetti (2004) a velocidade de germinação é um bom índice para avaliar a ocupação de uma espécie em um determinado ambiente, pois a germinação rápida é característica de espécies cuja estratégia é de se estabelecer no ambiente o mais rápido possível aproveitando condições ambientais favoráveis.

Yamagushi et al. (2011) também identificaram redução do IVG de sementes de alface quando submetidas ao tratamento com extrato aquoso de folhas de Eucalyptus grobulus. Carvalho et al. (2015), ao avaliar efeito alelopático de folhas de eucalipto em sementes de gramíneas constataram que o IVG de sementes de Urochloa decumbens e Panicum maximum apresentaram redução significativa em todas as concentrações do extrato, sendo mais evidente na maior concentração. A redução do índice de velocidade de germinação evidencia redução da expressão do vigor das sementes, devido ao efeito tóxico dos extratos (TUR et al., 2012).

O extrato aquoso de Eucalyptus grandis Hill ex Maiden não alterou o comprimento da parte aérea e da raiz de alface e picão-preto (Figura 2A e B). Porém, observou-se aumento de 370,8\% da biomassa fresca da alface e de 334,6\% da seca quando utilizou-se o extrato a 25\% (Figura 2C), indicando aumento no diâmetro das raízes e caulículo, verificado pela observação visual. 

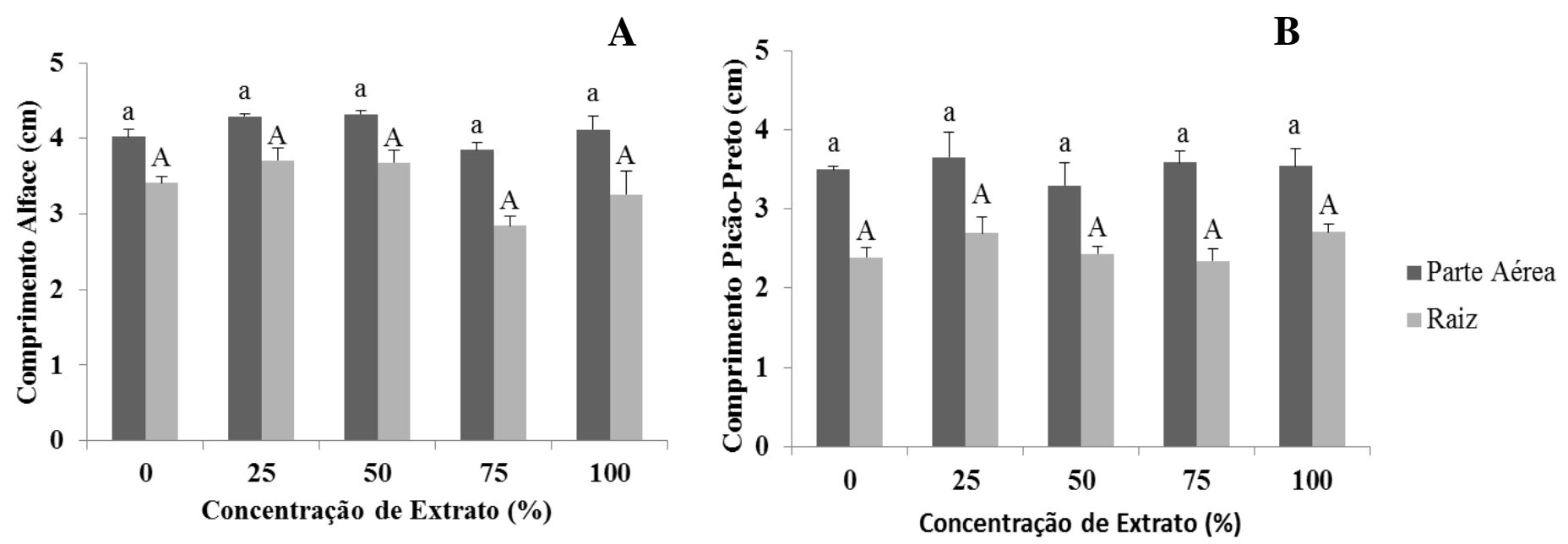

C
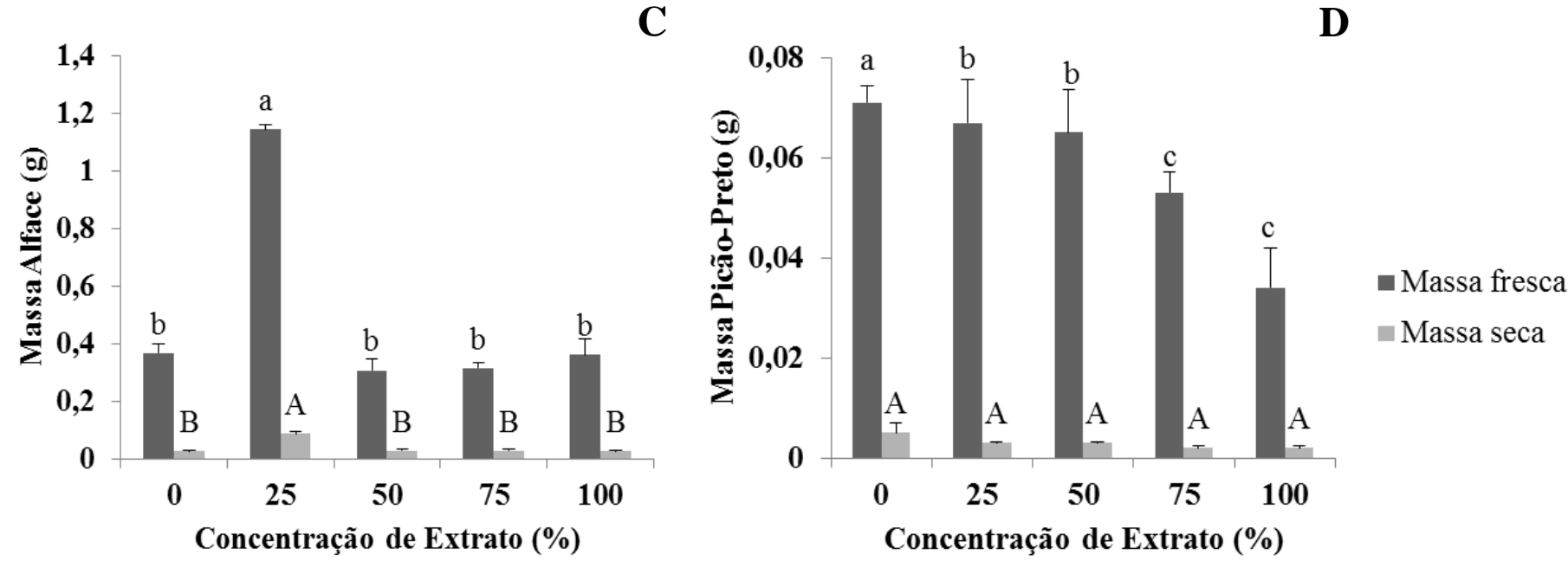

Figura 2 - Crescimento de plântulas de alface e picão-preto tratadas com diferentes concentrações $(0$, 25, 50, 75 e 100\%) de extrato aquoso de Eucalyptus grandis Hill ex Maiden durante sete dias. AComprimento da parte aérea e raiz de plântulas de alface. B - Comprimento da parte aérea e raiz de plântulas de picão-preto. C - Massa fresca e seca de plântulas de alface. D - Massa fresca e seca de plântulas de picão-preto. Médias com letras distintas diferem entre si $(\mathrm{p} \leq 0,05)$ pelo teste de Scott-Knott e as barras correspondem ao erro padrão (SE). Letras minúsculas referem-se ao comprimento da parte aérea nas figuras $\mathrm{A}$ e $\mathrm{B}$ e a massa fresca nas figuras $\mathrm{C}$ e $\mathrm{D}$, enquanto letras maiúsculas ao comprimento da raiz nas figuras $\mathrm{A}$ e $\mathrm{B}$ e a massa seca nas figuras $\mathrm{C}$ e $\mathrm{D}$.

Em relação a biomassa do picão-preto, notou-se efeito alelopático negativo do extrato, reduzindo a biomassa fresca das plântulas em todas as concentrações analisadas, com redução de 32,7\% no tratamento com $100 \%$ de extrato aquoso, entretanto, não foi ocorreu alterações significativas na biomassa seca (Figura 2D). Provavelmente o extrato interferiu no potencial osmótico e consequentemente prejudicou a absorção de água pelas radículas das plântulas de picão-preto. 
Ferreira et al. (2007) também não detectaram redução no comprimento radicular da alface e picão-preto quando testaram extratos de Eucalyptus citriodora Hook, independentemente das concentrações testadas, corroborando os dados obtidos no presente estudo. Os mesmos resultados foram obtidos por Aleixo et al. (2016) ao avaliar o potencial alelopático de folhas frescas ou serapilheira de eucalipto Corymbia citriodora utilizando alface como planta teste, sendo que os tratamentos não afetaram o comprimento da raiz e nem o comprimento da parte aérea. Contudo, Goetze e Thomé (2004) verificaram diminuição no crescimento de alface, repolho e brócolis quando utilizaram extratos aquosos de Eucalyptus globulus.

As investigações de plantas com atividade alelopática podem ser úteis na busca de fitotoxinas com potencial para compor herbicidas naturais que diminuam prejuízos provocados por plantas invasoras e reduzam impactos ambientais (PEREIRA et al., 2017), sendo de grande importância a realização de pesquisas nesse campo para se conhecer os mecanismos de ação, produção e decomposição de compostos alelopáticos. Os recentes avanços na química de produtos naturais, por meio de métodos modernos de extração, isolamento, purificação e identificação, têm contribuído bastante para um maior conhecimento desses compostos secundários (FERREIRA e ÁQUILA, 2000).

Os resultados desta pesquisa indicaram que, apesar de interferir negativamente na porcentagem de germinação, a concentração de $25 \%$ do extrato aquoso de Eucalyptus grandis Hill ex Maiden provocou menores danos a alface e aumentou expressivamente a biomassa das plântulas, sugerindo que esta concentração provavelmente pode ser utilizada em sistemas agrícolas. Entretanto, são precisos estudos que verifiquem as interações entre Eucalyptus grandis Hill ex Maiden e outras plantas daninhas, considerando que pesquisas como a de Silva et al. (2015) que mostrou que o eucalipto pode ter efeito alelopático sobre corda de viola (Ipomoea purpurea L.).

Também há necessidade de estudos complementares com utilização de diferentes solventes e maneiras para obtenção dos extratos, através de ensaios em casa de vegetação e até mesmo em campo, com vistas à bioprospecção de moléculas de interesse agronômico, através de fracionamento e isolamento para sua utilização como bioherbicidas.

\section{CONSIDERAÇÕES FINAIS}

Os resultados sugerem que Eucalyptus grandis Hill ex Maiden não apresenta potencial alelopático em relação ao picão-preto e a baixas concentrações pouco influencia a germinação e o Revista Valore, Volta Redonda, 4 (Edição Especial): I- $14 ., 2019$ 
crescimento inicial de alface, planta sensível e utilizada em bioensaios. Considerando os efeitos do extrato de eucalipto em outros estudos que indicam que esta planta reduz a propagação e disseminação de plantas daninhas, talvez, este extrato em baixas concentrações pode ser utilizado como complemento na formulação de novos bioherbicidas a serem utilizados em sistemas olerícolas.

\section{Referências}

ALEIXO, S.; NASCIMENTO, M.T.; BARROSO, D.G. Potencial alelopático de Corymbia citriodora (Hook.) K.D. Hill \& L.A.S. Johnson sobre o estabelecimento de plântulas de espécies arbóreas de Mata Atlântica. Iheringia Série Botânica, v. 71, n. 3, p. 277-282, 2016.

ALMEIDA, F.S. A alelopatia e as plantas. Londrina: IAPAR, 1988. $60 \mathrm{p}$.

ALMEIDA, V.E.S.; CARNEIRO, F.F.; VILELA, N. J. Agrotóxicos em hortaliças: segurança alimentar, riscos socioambientais e políticas públicas para promoção da saúde. Tempus Actas em Saúde Coletiva, v. 4, n. 4, p. 84-99, 2009.

ALVES, L.L.; OLIVEIRA, P.V.A.; FRANÇA, S.C.; ALVES. P.L.C.; PEREIRA, P.S. Atividade alelopática de extratos aquosos de plantas medicinais na germinação de Lactuca sativa L. e Bidens pilosa L. Revista Brasileira de Plantas Medicinais, v. 13, n. 3, p. 328-336, 2011.

ALVINO, C.A.; GRICIO, L.H.; SAMPAIO, F.A.; GIROTTO, M.; FELIPE, A.L.S. Interferência e controle de plantas daninhas nas culturas agrícolas. Revista Científica Eletrônica de Agronomia, n. 20, p. 1-4, 2011
ARAUJO, H.J.B.; MAGALHÃES, W.L.E.; OLIVEIRA, L.C.O. Durabilidade de madeira de eucalipto citriodora (Corymbia citriodora (Hook.) K.D. Hill \& L.A.S. Johnson) tratada com CCA em ambiente amazônico.

ACTA Amazonica, v. 42, n. 1, p. 49-58, 2012.

BARTOLOME, A.P.; VILLASEÑOR, I.M.; YANG, W.C. Bidens pilosa L. (Asteraceae): Botanical Properties, Traditional Uses, Phytochemistry, and Pharmacology. Evidence-Based Complementary and Alternative Medicine, p. 1-51, 2013.

BORELLA, J.; PASTORINI, L.H. Influência alelopática de Phytolacca dioica L. na germinação e crescimento inicial de tomate e picão-preto. Biotemas, v. 22 , n. 3 , p. 67-75, 2009.

BRASIL. 2009. Ministério da Agricultura, Pecuária e Abastecimento. Regras para análise de sementes. Secretaria de Defesa Agropecuária. - Brasília: MAPA/ACS, 2009. 399 p.

CARVALHO, F.P.; MELO, C.A.D.; MACHADO, M.S.; DIAS, D.C.F.S.; ALVARENGA, E.M. The allelopathic 
effect of Eucalyptus leaf extract on grass forage seed.

Planta Daninha, v. 33, n. 2, p. 193-201, 2015.

CARVALHO, J.B.; SABBAG, O.J. Análise de eficiência da produção de alface no noroeste de São Paulo, Revista Agroambiente, v. 9, n. 2, p. 152-160, 2015.

CASSAL, V.B.; AZEVEDO, L.F.; FERREIRA, R.P.; SILVA, D.G.; SIMÃO, R.S. Agrotóxicos: uma revisão de suas consequências para a saúde pública. Revista Eletrônica em Gestão, Educação e Tecnologia Ambiental, v. 18, n. 1, p. 437-445, 2014.

COSTA, E.M.; CAVALCANTE, U.R.; SILVA, A.M.; PEREIRA, L.S.; VENTURA, M.V.A.; de CARVALHO, N.M.; FRANCO, H.P. Efeito alelopático de extratos aquosos de folhas de mangueira sobre a germinação e crescimento das plântulas de alface. Ipê Agronomic Journal, 3(1), 47-58. 2019.

CREMONEZ, F.E.; CREMONEZ, P.A.; CAMARGO, M.P.; FEIDEN, A. Principais plantas com potencial alelopático encontradas nos sistemas agrícolas brasileiros. Acta Iguazu, v. 2, Suplemento, p. 70-88, 2013.

CUNHA, J.L.X.L.; FREITAS, F.C.L.; COELHO, M.E.H.; SILVA, M.G.O.S.; MESQUITA, H.C.; SILVA, K.S. Períodos de interferência de plantas daninhas na cultura do pimentão nos sistemas de plantio direto e convencional. Revista Agroambiente, v. 9, n. 2, p. 175183,2015
DECHOUM, M.S.; ZILLER, S.R. Métodos para controle de plantas exóticas invasoras. Biotemas, v. 26, n. 1, p. 69-77, 2013.

DIAMANTE, M.S.; JÚNIOR, S.S.; INAGAKI, A.M.; SILVA, M.B.; DALLACORT, R. Produção e resistência ao pendoamento de alfaces tipo lisa cultivadas sob diferentes ambientes. Revista Ciência Agronômica, v. 44, n. 1, p. 133-140, 2013.

FERREIRA A.G; AQUILA M.E.A. Alelopatia: Uma área emergente da ecofisiologia. Revista Brasileira de Fisiologia Vegetal. 12 (Edição Especial), p. 175-204. 2000 .

FERREIRA, A.G.; BORGHETTI, F. Germinação: do básico ao aplicado. Porto Alegre: Artmed, 2004. 323 p..

FERREIRA, D.F. Sisvar: a computer statistical analysis system. Ciência e Agrotecnologia, v. 35, n. 6, p. 10391042, 2011.

FERREIRA, M.C.; SOUZA, J.R.P.; FARIA, T.J. Potenciação alelopática de extratos vegetais na germinação e no crescimento inicial de picão-preto e alface. Ciência e Agrotecnologia, v. 31, n. 4, p. 10541060, 2007.

FORMAGIO, A.S.N.; MASETTO, T.E.; VIEIRA, M.C.; ZÁRATE, N.A.H.; COSTA, W.F.; TREVIZAN, L.N.F.; SARRAGIOTO, M.H. Potencial alelopático de Tropaeolum majus L. na germinação e crescimento inicial de plântulas de picão-preto. Ciência Rural, v. 42, n. 1, p. 83-89, 2012. 
GILBERT, B.; ALVES, L.F.; FAVORETO, R. Bidens pilosa L. Asteraceae (Compositae; subfamília Heliantheae). Revista Fitos, v. 8, n. 1, p. 53-67, 2013.

GILlES, M.; ZHAO, J.; AN, M.; AGBOOLA, S. Chemical composition and antimicrobial properties of essential oils of three Australian Eucalyptus species. Food Chemistry, v. 119, n. 2, p. 731-737, 2010.

GOETZE M; THOMÉ GCH. Efeito alelopático de extratos de Nicotiana tabacum e Eucalyptus grandis sobre a germinação de três espécies de hortaliças. Revista Brasileira de Agrociência. v. 10, p. 43-50. 2004.
GOLDFARB, M.; PIMENTEL, L.W.; PIME, N.W. Alelopatia: relações no agroecossistemas. Revista Tecnologia e Ciência Agropecuária. v.3, n.1, p.23-28, 2009

GONÇALVES, V.D.; COELHO, M.F.B.; CAMILI, E.C. Bioensaios em sementes de Lactuca sativa L. com extrato de folhas de Kielmeyera coriácea Mart. \& Zucc.. Revista Internacional de Ciências, v. 6, n. 2, p. 160-170, 2016.

GRISI, P.U.; RANAL, M.A.; GUALTIERI, S.C.J.; SANTANA, D.G. Allelopathic potential of Sapindus saponaria L. leaves in the control of weeds. Acta Scientiarum. Agronomy, v. 34, n. 1, p. 1-9, 2012.

GUSMAN, G.S.; VIEIRA, L.R.; VESTENA, S. Alelopatia de espécies vegetais com importância farmacêutica para espécies cultivadas. Biotemas, v. 25, n. 4, p. 37-48, 2012.

HAIDA, K.S.; BARON, A.; DA SILVA, F.J.; DE LIMA ARCELES, M.; FERNANDES, A.; ANDREAZZA, A.P.; DA COSTA, J.H.B. Propriedade sequestrante de radicais livres e determinação do teor de fenólicos totais da sálvia e eucalipto. Saúde e Pesquisa, v.4, n.1. 2011.

KLEIN, F.R.S.; MARTINAZZO, E.G.; PEDÓ, T.; AUMONDE, T.Z.; VILLELA, F.A. Performance de sementes e plântulas de alface sob ação alelopática de extratos de raízes de ginseng brasileiro. Revista Tecnologia \& Ciência Agropecuária, v. 8, n. 5, p. 3943, 2014. 
MARCON, T.R.; FORTES, A.M.T.; RIBEIRO, V.; HARTMANN, K.; SUSZEK, F. Efeito alelopático de Eucalyptus orophila L. D. Pryor sobre a germinação e crescimento da soja. Journal of Agronomic Sciences, v. 5, n. 1, p. 245-253, 2016.

MOREIRA, H.J.C.; BRAGANÇA, H.B.N. Manual de identificação de plantas infestantes: hortifrúti. Campinas: FMC Agricultural Products, 2011. 1017 p.

PARENTE, K.M.S.; PARENTE FILHO, E.G.; SILVA, E.V. Alelopatia de Ziziphus joazeiro Mart. sobre Lactuca sativa L. e Lycopersicon esculentum Mill. Revista fitos, v. 9, n. 2, p. 79-86, 2015.

PEREIRA, G.A.M.; MACIEL, J.C.; DOS SANTOS, J.B.; DOS REIS, R.F.; FERREIRA, E.A. Interferência de plantas daninhas no crescimento da cultura do trigo. Journal of Neotropical Agriculture, v.4, n.3, p. 23-29, 2017.

PEREIRA, M.R.R.; TEIXEIRA, R.N.; SOUZA, G.S.F.; SILVA, J.I.C.; MARTINS, D. Inibição do desenvolvimento inicial de plantas de girassol, milho e triticale por palhada de capim-colchão. Planta Daninha, v. 29, n. 2, p. 305-310, 2011.

SALDANHA, L.L. Prospecção química e avaliação das atividades antioxidante e alelopática de Myrcia bella Cambess 161f. Dissertação de Mestrado. Universidade Estadual Paulista "Julio de Mesquita Filho". Botucatu, SP. 2013.
SANTOS, J.B.; CURY, J.P. Picão-preto: uma planta daninha especial em solos tropicais. Planta Daninha, v. 29, p. 1159-1171, 2011.

SCOTT, A.; KNOTT, M. Cluster-analysis method for grouping means in analysis of variance. Biometrics. v. 30, n. 3, p. 507-512. 1974.

SEBEI, K.; SAKOUHI, F.; HERCHI, W.; KHOUJA, M.L.; BOUKHCHINA, S. Chemical composition and antibacterial activities of seven Eucalyptus species essential oils leaves. Biological Research, v. 48, n. 7, p. 1-5, 2015.

SHETTA, N.D.; ALSHAHRANI, T.S.; AREF, I.M.; NASSER, R.A. Allelopathic potential of Calotropis procera and Ecucalyptus species on germination and growth of some timber trees. Allelopathy Journal, v. 40, n. 1, 2017.

SILVA, E.S.; SANTOS, C.A.; DIAS, K.S.; SOUZA, M.A.; DOS SANTOS, A.F.; JÚNIOR, J. M. S. Cenário das pesquisas sobre alelopatia no Brasil e seu potencial como estratégia na diminuição da utilização de pesticidas que provocam poluição ambiental: uma revisão integrativa. Diversitas Journal, v.3. n.2, p.442454. 2018.

SILVA, F.L.; FISCHER, D.C.H.; TAVARES, J.F.; SILVA, M.S.; ATHAYDE-FILHO, P.F.; BARBOSAFILHO, J.M. Compilation of Secondary Metabolites from Bidens pilosa L. Molecules, v. 16, n. 2, p. 10701102, 2011. 
SILVA， I.C.; SILVA， V.M.; FERREIRA， V.M.; ENDRES, L. Efeito alelopático do extrato de folhas de (Eucalyptus grandis) sobre a germinação de sementes de (Ipomoea purpurea L.). Cadernos de Agroecologia, v. 10, n. 2, 2015.

SOARES, M.M.; FREITAS, C.D.M.; OLIVEIRA, F.S.; MESQUITA, H.C.; SILVA, T.S.; SILVA, D.V. Effects of competition and water deficiency on sunflower and weed growth. Rev. Caatinga, Mossoró, v. 32, n. 2, p. 318328, 2019.

SOUZA V.M.; CARDOSO S.B. Efeito Alelopático do extrato de folhas de Eucalyptus grandis sobre a germinação de Lactuca sativa L. ( alface) e Phaseolus vulgaris L. (feijão). Revista Eletrônica de Educação e Ciência (REEC), v.3, n.2, p. 01-06. 2013.

TOLEDO, M.Z.; LEME, F.M.; SOARES, R.B. Potencial alelopático da serrapilheira de eucalipto e estabelecimento de plântulas de soja. Cadernos de Agroecologia, v.13, n.2, 10-10. 2018.

TUR, C.M.; MARTINAZZO, E.G.; AUMONDES, T.Z.; VILLELA, F.A. Atividade alelopática de extratos aquosos de folhas de rabo-de-bugio sobre a germinação e o crescimento inicial de plântulas de alface. Revista Brasileira de Biociências, v.10, n.4, p. 521-525, 2012.

VASCONCELOS, M.C.C.; SILVA, A.F.A.; LIMA, R.S. Interferência de plantas daninhas sobre plantas cultivadas. Agropecuária Científica no Semiárido, v.8, n.1, p. 1-6, 2012.
YAMAGUSHI, M.Q.; GUSMAN, M.S.; VESTENA, S. Efeito alelopático de extratos aquosos de Eucalyptus globulus Labill. e de Casearia sylvestris Sw. sobre espécies cultivadas. Semina: Ciências Agrárias, v. 32, n. 4, p. 1361-1374, 2011.

ZERA, F.S.; BETTIOL, J.V.T.; de BARROS SANT'ANNA, C. Efeito alelopático de capim-camalote no desenvolvimento inicial de alface e capim-colonião. Nucleus, v.16, n.1, p. 147-154. 2019. 
Recebido em: 20/09/2019

Aceito em: 09/11/2019

Endereço para correspondência:

Nome: Graciene de Souza Bido

Email: gsbido@hotmail.com

\section{(c) (†)}

Esta obra está licenciada com uma Licença $\underline{\text { Creative }}$ Commons Atribuição 4.0 Internacional. 